havia evoluldo para uma espécie de plebiscito demagógico entre falsos lideres populares, que exploravam as paixōes coletivas. No Brasil, o sistema presidencial encontra-se num verdadeiro impasse: sua coluna mestra é a liderança popular do Presidente; liderança popular corresponde à eleição; a eleição direta de um presidente no Brasil, por sua vez, provoca cada vez mais crises. Por outro lado,

presidencialismo com eleição indireta, alemı de ser uma farsa, provocará no povo frustraçōes que passarāo a reações só domináveis pela fôrça. Isto na medida em que "o ato de votar em um candidato à presidência significava um desabafo imediato, a oportunidade de um revide contra as dificuldades da vida, ou, no máximo, um anelo informulado de melhoria particular e imediatista, desligada de qualquer visão mais geral ou distante". Para o autor, o agrupamento das massas atraidas somente pelo carisma demagógico ou pelo benefício urgente é o que a conscientização social da era de Getúlio Vargas legara à liberdade eleitoral.

A saída para o parlamentarismo, com efeito, visava especificamente a resolver o problema político brasileiro: nesse aspecto êle é negativo, pois a mudança institucional não foi executada com plena consciência do seu valor, mas toi considerado pelo Congresso mais como um expediente político. 0 seu lado positivo está na saída legal para a crise que ameaçava a liberdade.

Com o parlamentarismo, o autor é nomeado Embaixador do Brasil na ONU, onde vai continuar a imprimir o mesmo tom independente à nossa política externa. Mostra que com essa linha de ação, o Brasil ganhava prestígio e confiança internacionalmente. No entanto, do ponto de vista interno, o País estava dividido pelas elites dirigentes, que fazem agitação e forçam a volta ao presidencialismo.

Relata com minúcias todos os acontecimentos que deram origem ao plebiscito e que possibilitaram a volta ao antigo regime e mostra seu pessimismo diante dos rumos tomados pela política interna.

Com a sua volta ao Senado, vai dar-nos um relato das missóes estrangeiras de que participou e da sua atuação no Congresso, até a Revolução de 1964. A partir daí, mostra tôda a sua atuação para a volta do Brasil a uma política externa independente $\mathrm{e}$ de não-alinhamento e uma volta ao regime democrático por meio de uma Constituição que não estivesse desvinculada da nossa realidade política, social e econômica.

o livro do Sr. Afonso Arinos de Melo Franco é importante leitura para quem queira conhecer mais detalhadamente os fatos de nossa história política contemporânea. Num estilo elegante, suas memórias não escondem uma certa nostalgia por um passado patriarcal, quebrado por novos valôres; ao mesmo tempo, deixa clara a sua posição de homem liberal a procura de uma democracia sem mistificações, baseada em novos valôres morais.

EVALDO SINTONE

\section{DESENVOLVIMENTO DA}

\section{CIVILIZACAAO MATERIAL NO BRASIL}

Por Afonso Arinos de Melo Franco. 2. ed., Conselho Federal de Cultura, 1971. 168 p. il.

A primeira edição do livro de Afonso Arinos é de 1944 e foi editada pelo Servico do Patrimánio Histórico e Artístico Nacional; a reedição transcreve o original. Apesar de não ter pretendido atualizá-lo, continua a ser indispensável para o estudo de algumas características da civilização brasileira.

O autor não pensou em fazer estudo exaustivo sôbre os temas que aborda, porém, a obra permanece como introdução a questões pouco abordadas da nossa historiografia. Como esta desenvolveu mais os estudos de história política, pouco sabemos de nossa evolução material. E assim que as conferências apresentam interêsse particular, pois tratam cronològicamente dos problemas da população, da urbanização, do povoamento, da administração, da comunicação, etc., fato que nos permite ter uma visão geral $e$ conjunta dêstes fenômenos. Por razōes particulares, estuda êstes fatôres por etapas: com exceção da primeira parte, que é um apanhado genérico - fatôres primitivos, o português, o negro, o indio - os outros capítulos referem-se aos séculos XVI, XVII, XVIII e XIX.

Para caracterizar o problema da ocupação portuguêsa na época Colonial, Afonso Arinos acentua traços que representam a

continuidade ou descontinuidade da permanência lusa no Brasil: "a preocupaçäo primordial dessa política de reprodução dos modelos reinóis foi, naturalmente, a fundação de povoaçöes fixas, que viessem substituir com vantagem os pousos móveis precários das feitorias. Portugal queria, pois, transplantar para cá as suas próprias povoações. E o fêz com tal vigor que ainda hoje êstes elementos fundamentais da nossa civilização material, as cidades do interior, guardam, em linhas gerais, a marca poderosa dos primitivos povoadores."

Por sua vez, as estradas - ou caminhos, como são denominadas comumente - deixam de ser cuidadas, simplesmente por razöes táticas: "por vários motivos, o português näo cưidou particularmente do sistema de comunicação terrestre. A princípio principalmente porque, sendo a civilização localizada na fímbria litorânea, mais fáceis e mais seguras eram as comunicacöes marítimas... Depois, o latifúndio e a monocultura, na era açucareira, a falta de trocas internas e o insulamento econômico dos engenhos em nada contribuíram para melhorar os caminhos... Em seguida à era da cana, o século do ouro aínda menos contribuiu para a melhoria delas. Caminhos, então, só os indispensáveis, pois quanto mais caminhos houvesse mais se facilitariam os descaminhos do metal e das pedras, em prejuizo do físco vigilante".

No entanto, além da problemática comum das cidades e caminhos, temos a existência de outros fatôres, como o gôsto portugués pela ostentação exterior e sua mediocre preocupação pelo confôrto interno de moradia.

O século XVI é aquêle em que o povoador ocupa grande parte da faixa litorânea: o reconhecimento das costas, as feitorias, as capitanias hereditárias e o Govêrno-geral são medidas diversas, com objetivos únicos, isto é, povoamento das regiōes ameaçadas pelos estrangeiros. E as inúmeras cidades fundadas nesta centúria mostram também a preocupação em fixar o homem em pontos estratégicos: é Tomé de Sousa quem abre a "nova fase para a civilização brasileira". pois êle tem os "recursos mais amplos da Coroa". Assim, de maneira genérica, temos as fundações das cidades de Salvador (1549), São Paulo (1554), São Vicente (1532), Rio de Janeiro (1565), Olinda (1536), Santos (1546), etc.

O século XVII foi o "mais importante da nossa história Colonial, pois nêle se deu a consolidação do domínio luso no litoral, com a expulsão dos invasores, e, no interior, a parte decisiva da conquista do sertäo". Assim é que, dentro dêste contexto dá-se a transformação do Recife, sob Maurício de Nassau; por outro lado, a Bahia, centro da zccão de Portugal, torna-se a "cabeça da Colônia".

A defesa costeira explica, em parte. desenvolvimento urbano litorâneo. No interior, o fenômeno é diferente: "o ciclo da caça ao índio é

essencialmente móvel. 0 bandeirante não se fixa, năo funda

estabelecimentos duráveis. Penetra, luta, encurrala o seu rebanho humano e regressa com êle para o litoral". Porém, só certos núcleos ou pousadas dos bandeirantes, ligados a caminhos mais permanentes, é que irão transformar-se em cidades: Mogi das Cruzes (1611), Taubaté (1650), Jacareí (1653) e Guaratinguetá (1657)

"comandavam o avanco para as

Gerais; Parnaiba (1625) e Itu (1657)

foram os trampolins do salto a Mato Grosso; Jundial e Sorocaba (1661) 
apontavam respectivamente os caminhos de Goías e Paraná".

O século XVIII é aquêle em que se completa o povoamento do litoral e o reconhecimento do interior aprofunda-se. $O$ gado no Rio Grande do Sul e no vale do São Francisco; o ouro e diamantes em Minas Gerais, Goiás e Mato Grosso; a ocupação militar e religiosa do vale do Amazonas, etc. são alguns momentos da maior fixação interiorana. Nesse período, a civilização - arte, moradia, urbanização, luxo - toma aspectos novos. $\mathbf{E} 0$ desenvolvimento particularista vai consolidar-se, numa afirmação de regionalismo, que marcará a nossa história.

"Nos primeiros anos do século passado $(X \mid X)$ dá-se um fato de capital importância para o desenvolvimento da civilização brasileira. O Brasil, de administração secundária, passa a ser sede do Govênno; de colônia se transforma em metrópole, entrando de chofre, sem luta, no estado de independência polltica. Qualquer critica pessoal que se pretender fazer ao príncipe e rei D. Joäo perde o interêsse diante da realidade poderosa do movimento progressista que a sua funcão governativa produziu, se nâo mesmo promoveu. A estada da côrte no Rio de Janeiro foil a origem de uma transformaçăo profunda da civilização do Brasil".

O reflexo maior aparece, inicialmente, na transformaçäo material do Rio de Janeiro: sua população, no têrmo do século XVIII, pouco excedia de 40.000 habitantes; em 1821 atinge 110.000 almas. "Não sòmente cresce a cidade como também fol provida de edifícios públicos e particulares, dotados de estilo arquitetônico mais apurado, graças a presença do arquiteto Grandjean de Montigny, elemento integrante da missão artística francesa aqui chegada em $1816 "$ "

As outras capitais - Pôrto Alegre, Salvador, Recife, São Paulo - sofrem também grandes vicissitudes nesse século. Porém, é o café que intensifica o comércio, a urbanizaçäo e a abertura de estradas de ferro no sul. No Nordeste, o acúcar ainda representa o elo econômico fundamental e, conseqüentemente, é a partir dêle que se explica uma série de transformaçöes materiais.

Assim, o breve apanhado de Afonso Arinos permite-nos seguir o nascimento e desenvolvimento de uma série de problemas materiais da nossa civilização. $E$, o seu livro pioneiro, torna-se grandemente útil como introdução à problemática da história brasileîra.

EDGARD CARONE

\section{NARRATIVAS DE UMA VIAGEM} AO BRASIL

Por Tomas Lindley. São Paulo, Companhia Editôra Nacional, 1969. 190 p. (Col. Brasiliana, 343).

Publicado originàriamente em Londres, em 1805, o livro de Lindley reúne seu diário de permanência em Pôrto Seguro e Salvador lugares onde estêve prisioneiro, de julho de 1802 a agôsto de 1803 - e notas históricas sôbre o Brasil. E um dos primeiros relatos de estrangeiros publicados no século $X I X$, tendo, assim, servido de fonte para inúmeros estudiosos e viajantes, que utilizarāo fartamente suas informações verídicas e precisas. Andrew Grant, em Description of Brazil plagia fatos revelados pelo nosso autor; $e$ os franceses Hipplolyte Taunay e Fernando Denis citam constantemente o mercador inglês.

Durante a sua permanência forçada no Brasil - Lindley é prêso quando contrabandeava pau-brasil nas costas da Bahia - anota, com argúcia e sensibilidade, as peculiaridades e costumes existentes. Suas observaçōes sóbre a economia, instituiçôes, religião, costumes, etc. são precisas e claras. Dal o interêsse de sua obra, que é documentário vivo de um momento.

Um fato inicial e fundamental surge do diário: a existência de um comércio de contrabando ativo entre a Bahia, Rio de Janeiro e a bacia do Prata. Apesar das medidas repressivas portuguêsas, o contato com Buenos Aires é constante. E quem ajudava a praticar o contrabando eram as pessoas "nomeadas para impedi-1o", isto $\hat{e}$, as autoridades militares portuguêsas ou "indivíduos por êles acumpliciados".

O contrabando é também comprovado pelo grande número de navios estrangeiros, principalmente inglêses, que navegam ou aportam às costas brasileiras. Naturalmente que nem todos têm o mesmo objetivo, mas a presença suspeita dêles em certas regiōes da Bahia comprova o fato. Durante a estadia de Lindley, um navio inglês naufraga na baía de Santa Cruz, outro ao sul da Bahia e três aportam avariados ao pôrto de Salvador.

A justiça portuguêsa aparece descrita de maneira dramática, surgindo com todo o seu sistema complexo e obsoleto: desde o seu apresamento o autor tem de sofrer as conseqüências de um complicado sistema judicial. E prêso e confronta-se com o desembargador do crime, o capitão da Marinha e os escreventes da justiça; sua mercadoría é apreendida, sendo avaliada ao bel-prazer das autoridades; as inquisiçôes são lentas e constantes e "um tribunal de justiça que decide a questão e pronuncia a sentença. Em alguns casos, há o recurso de apelação ao Tribunal Superior de Lisboa ou aे clemência do príncipe". As mercadorias apresadas servem para ajudar a pagar as despesas do processo, só que sua avaliaçăo cabe aos portuguêses: um dos navios avariados é obrigado a descarregar, "sob a imediata superintendência e inspeção do guarda-mor e de um amanuense da Alfândega. Mas não The poderia ser concedida a faculdade de realizar vendas a fim de liquidar suas despesas porque haviam chegado ordens recentes de Lisboa para que, nesses casos, uma suficiente quantidade de mercadorias fôsse retirada do navio e mandada para essa cidade, sendo lá vendida.

A divida de origem, o frete para a Europa e as despesas de viagem seriam deduzidas do produto dessa venda e o saldo (se houvesse) devolvido ao proprietário, em Londres ou qualquer outra parte".

Ainda aparece como precária a ocupação plena do território pelos portuguêses: apesar das regiōes de Pôrto Seguro e Salvador terem sido ocupadas desde o século XVI, índios ainda atacam a primeira das duas cidades. A zona, porém, está semeada por grande número de engenhos $e$ agricultores. A descrição das propriedades comprova que grande número delas possui "fábrica de acúcar", com engenhos de "três cilindros de pesada madeira"; outras são "fazendolas esparsas, situadas nas proximidades do rio, para melhor transporte de seus produtos destinados a Pôrto Seguro"; e algumas produzem a mandioca, "raiz inestimável, pois proporciona a farinha ou o päo da América do Sul".

A vida urbana também é descrita de maneira rica. A existência da burguesia comercial é exemplificada pela sinalização de alguns nomes de seus representantes mais dinâmicos, como o de Antônio da Silva Lisboa, que mantém grande contacto com a Inglaterra. Outro comerciante que aparece possui belo jardim na sua residência e tem "fortuna ilimitada".

Porém, outro dado fornecido por Lindley também é de fundamental importância: a comprovação da existência de pessoas que guardavam grande fortuna, emprestavam dinheiro a juros e faziam serviço de câmbio. Esta forma de acumulação de capitais é que permitirá o nascimento do sistema de comissários de café, comissários de açúcar, etc., isto é, a formação de um sistema pré-bancário no Brasil. Por exemplo, o Sr. Oliveira vendia chitas as suas freguesas e quando "apresentei meu título, e assisti a quantia ser contada com muito cuidado e empilhada (sendo em prata) num banco que ficava por detrás dêle, coberto com um pano. Informando eu ao velho que me havia sido prometido ouro, êle transportou uma parte da prata para o armário já mencionado e, abrindo-o, fiquei 